\title{
Simulation Studies on Comparative Evaluation of Waterflooding and Gas Injection in Niger Delta Thin-Bed Reservoir
}

\author{
Ubanozie Julian Obibuike, Anthony Kerunwa, Mathew Chidube Udechukwu, \\ Stanley Toochukwu Ekwueme
}

Department of Petroleum Engineering, Federal University of Technology, Owerri, Nigeria

Email: stanleyekwueme@yahoo.com

How to cite this paper: Obibuike, U.J., Kerunwa, A., Udechukwu, M.C. and Ekwueme, S.T. (2022) Simulation Studies on Comparative Evaluation of Waterflooding and Gas Injection in Niger Delta Thin-Bed Reservoir. Open Journal of Yangtze Gas and Oil, 7, 6583.

https://doi.org/10.4236/ojogas.2022.71005

Received: September 13, 2021

Accepted: January 27, 2022

Published: January 30, 2022

Copyright $\odot 2022$ by author(s) and Scientific Research Publishing Inc. This work is licensed under the Creative Commons Attribution International License (CC BY 4.0).

http://creativecommons.org/licenses/by/4.0/

\begin{abstract}
There is a need to increase ultimate recovery from petroleum reservoirs. In order to guarantee efficient resource extraction from reservoirs, primary recovery methods cannot be relied on throughout the life of a well. There is a time in the life of a reservoir when the primary energy will not be sufficient to ensure economic recovery. Complete abandonment of the reservoir at this point may not be a sound engineering decision given the huge investments in developing the asset. Secondary recovery methods present potentials for the recovery of the other trapped resources. The choice of the secondary recovery means depends on the reservoir and geologic conditions and should be determined by modeling and simulation. In this work, a simulation study is conducted for Niger Delta Field ABX2 to determine the performance of waterflooding and gas injection in the recovery of the asset after the primary recovery stage. ECLIPSE Blackoil simulator was used for the modeling and simulation. An equal reservoir rectangular grid block was designed for both the waterflooding and water injection comprising a total of 750 grid cells. Water and gas were injected in both cases at an injection rate of $11,000 \mathrm{stb} / \mathrm{d}$ and $300,000 \mathrm{scf} / \mathrm{d}$ for waterflooding and gas injection respectively. From the results of the simulation, it was realized that waterflooding gave a higher total oil recovery than gas injection. The difference in oil recovery from waterflooding and gas injection amounted to $0.08 \mathrm{MMstb} / \mathrm{d}$. The Field Oil Recovery Efficiency (FOE) for waterflooding and gas injection was $38 \%$ and $16 \%$ respectively giving a difference of $22 \%$. The waterflooding method was troubled with excessive water cuts due to water breakthroughs. Waterflooding was chosen against gas injection to be applied to Field $\mathrm{ABX} 2$ to improve recovery after primary production ceased.
\end{abstract}




\section{Keywords}

Waterflooding, Gas Injection, Simulation, Recovery Efficiency, Ultimate Recovery

\section{Introduction}

Oil recovery from reservoirs is classified based on their drive mechanisms. This brings about the terms, primary, secondary, and tertiary recovery mechanisms. In most reservoirs especially in a conventional light oil reservoir, the primary recovery mechanism starts the productive life of the reservoir. Primary recovery entails the recovery of reservoir fluids utilizing the natural energy presented in the reservoir at the time of discovery. This natural energy usually comes from the initial high reservoir pressure which is a component of the aquifer support, the dissolved gas, the gas gap, or a combination of these factors [1] [2] [3].

During primary production, as the reservoir is produced, the energy of the reservoir gradually depletes, and there comes a time when the prevalent reservoir pressure would not be sufficient to guarantee the flow of fluids from the reservoir to the surface as it once was. On some occasions, the reservoir energy only suffice to flow fluids from the reservoir into the wellbore, and because of insufficient energy, these fluids accumulate in the wellbore and artificial lift techniques may be required to augment flow from the wellbore to the surface through the use of gas lift or artificial lift pumps [4] [5]. In this case, work is done in the tubing by injecting gas to lighten the fluid column and flow the aerated fluid to the surface, or the accumulated fluid is pressurized and flows to the surface is enabled. The application of gas lift is regarded as a part of primary production since no injection is done into the reservoir. It is the special continuation of the primary recovery. In other situations, the reservoir pressure may be too low to maintain economical production rate. In this case, a new means to supplement the reservoir energy is required. The reservoir energy in this case is usually boosted by the injection of fluids into the reservoir. The injection of reservoir fluids into the reservoir such as water or dry gas is known as the secondary recovery process while the injection of non-reservoir fluids like carbon dioxide, nitrogen, propane, steam, hot water, etc. are referred to as tertiary or enhanced oil recovery processes [6] [7].

In water injection methods of the secondary recovery process, the injected water can be for waterflooding or pressure maintenance. Although both processes look similar, they are different based on the stage of the reservoir in which they are applied to which affects their displacement process. If the water injection is done at a time in the reservoir when the reservoir pressure is still high, the injection process is referred to as a pressure maintenance project. However, if the water injection is done at a time when the reservoir pressure has declined to a low level due to primary depletion, the injection process is referred to as waterflooding. In 
both the pressure maintenance and waterflooding cases, there is a dynamic displacement of the reservoir fluid by the injected water [1].

Gas injection is another method of the secondary recovery process. In gas injection, dry gas is injected into the reservoir to displace oil. Since dry gas does not mix with oil, the process is a piston-like displacement process just as in water injection schemes.

Secondary recovery processes have been known to recover an additional 25\% to $45 \%$ of the oil in place after primary recovery. This has greatly increased the ultimate recovery from the reservoir and improved oil recovery economics. Waterflooding has been recognized as the most dominant fluid injection process. This can be attributed to the following reasons:

1) The general availability of injection water;

2) The relative ease and simplicity of waterflooding compared to injection processes;

3) The lower capital and operational expenses accruable to waterflooding as compared to other injection processes;

4) The favourable phenomena of water spreading in oil-bearing formations;

5) The efficiency of water in displacing oil;

6) The low risk of waterflood operation.

In secondary recovery processes, gas injection and waterflooding have often been compared. Because of the low viscosity of the gas, there is often a low mobility ratio which is not favourable in oil-displacement processes. Dry gas having less viscosity and density than water has tendencies of early fingering and breakthrough than water. Also, the technological requirement for gas injection is rather more complicated and costly than that for water [2] [8]. In the situation where injection gas has to be purchased because of competition from other gas utilization processes, the capital involved in a gas lift is greatly increased and in some cases, there may not be sufficient gas for injection. For waterflooding, water is generally available and easy to store, this gives it a great advantage over gas injection in the selection of adequate secondary recovery process to be applied to a depleted reservoir [9] [10] [11].

Despite the applausive factors that drive the waterflooding process; it is not without its challenges and limitations. The problem of water breakthroughs due to adverse mobility ratios leads to poor recoveries, especially in heavy oils. High water cut is predominant in waterflooding, this greatly impacts the economics of the recovery as water competes with oil during flow to the production interval. The additional cost of water handling and storage adds more challenges to the process. Furthermore, waterflooding has been notable with other production problems such as formation damage, scale deposition, corrosion problems. These problems ultimately lead to non-economical operations and reductions in oil production [12] [13] [14].

Many methods have been reported in literature aimed at optimizing oil recovery and water performance in waterflood oil recovery processes. Most of these 
production optimization procedures have been applied to small, simple, or even complex reservoirs using various models.

[15] conducted a study using a heterogeneous 2-dimensional reservoir model comprising of oil and water phases in two horizontal smart wells comprising of one producer and one injector. The wells were located at the extreme opposite sides of the reservoir. They developed a model for optimal control theory on waterflooding problems.

[16] conducted waterflooding optimization using multiple geological models. The model comprised a 3D, two-phase (oil \& water) reservoir with 18,553 active grid blocks, consisting of 7 geological layers. The model was fundamental in the investigation of closed-loop reservoir management and optimization methods. However, the optimization approach is non-linear and a large number of optimization variables might increase the chance of achieving a suboptimal solution.

[17] worked on increasing the efficiency of waterflooded reservoirs. He focused on equalization of the arrival times of the flood front at the producers with the sub-region selected. One of the striking advantages of their method was the ability to use single-phase flow simulations to analytically calculate the sensitivity of the arrival times for the production/injection rates. Their model was applied to the Goldsmith San Andres unit, they successfully reduced the water breakthrough by three years causing an increase in the cumulative oil production and also reducing the water production.

In their study, [18] applied the adjoint-based optimization waterflooding method to a reservoir in the Gulf of Mexico. The model was a 3D two-phase reservoir with 68,800 grid blocks (approximately 40,000 active grid blocks) containing 5 injectors and 5 producers. Their target was to maximize the field NPV by increasing the bottom hole pressure. Their work led to an increase in NPV of $17 \%$ for the field.

In this work, the potential of waterflooding and gas injection in the Niger delta oilfield is studied. A simulation approach is taken using ECLIPSE Blackoil 100 simulator.

\section{Notable Concepts in Secondary Recovery Processes}

Many concepts are important in the application of secondary recovery processes in reservoirs that have undergone primary depletion.

\subsection{Wettability}

Wettability in a rock/oil/brine system can be defined as the tendency of a fluid to preferentially adhere to or spread to the surface of a rock in the presence of other immiscible fluids. In waterflooding, the wetting phase can be oil or water. The rock is water-wet when water occupies the small pore and contacts the larger pores. The oil in this case resides in the location of the larger pores. In oil-wet, the oil resides in the small pores and contacts the larger pores occupied by the 
water [19] [20] [21]. Gas never wets the surface of the rock. Most of the world's reservoir rocks are water-wet with only a few being oil-wet. Primary recovery and waterflooding are highly favored in water-wet reservoirs [22]. In oil-wet reservoirs, the attractive forces between the rock surface and the oil tend to retard the movement of the oil resulting in higher residual oil saturation therefore and thus lower oil recovery. There are situations in the reservoir system when no preference is shown by the rock to either fluid (oil or water). This is a special case referred to as intermediate or neutral wettability. This condition is depicted as being equally wet by both fluids [23].

\subsection{Capillary Pressure}

Capillary pressure is the difference in pressure between two immiscible fluids at their interface due to varying fluid densities. In a petroleum reservoir, capillary forces result from the combined effect of surface and interfacial tensions of the rock and fluids, geometry and size of pores, and the wettability of the system [24]. The higher the interfacial tension the higher the capillary pressure. Capillary pressure is inversely proportional to pore size, therefore, the smaller the pore size the higher the capillary pressure. This implies that, the less permeable the reservoir the higher the capillary pressure [25].

\subsection{Surface/Interfacial Tensions}

These are the forces of interaction at the interfaces of two or more fluids in contact. These forces are caused by the unbalanced molecular attraction between molecules at their contact interfaces. If it is the liquid-gas interface, it is called surface tension. But if it is an immiscible liquid-liquid or gas-gas interface it is called interfacial tension. It is worthy to note that the magnitude of surface or interfacial tension depends on the fluid composition [1] [2] [3].

\subsection{Relative Permeability}

Relative permeability becomes important when one fluid flows in the presence of other fluids in the reservoir. The ability of the reservoir to transmit each of the fluids varies depending on the fluid properties. Relative permeability of a particular fluid is the ratio of its effective permeability to a base permeability (absolute permeability or permeability of air) of the porous medium. That is, the relative transmissibility of the various fluids when they are moving together [26].

\subsection{Mobility}

This is the ratio of the effective permeability of fluid to the viscosity of that fluid. Oil is usually more viscous than water, therefore, at the same effective permeability, water tends to be more mobile than oil and will tend to outrun the oil. The mobility ratio is an important factor in the calculation of flooding performance. The mobility ratio is defined as the mobility of the displacing phase divided by the mobility of the displaced phase. A mobility ratio of less than or equal to 1 is 
favourable and always sought for. This signifies that the oil is more mobile than or as mobile as the water and translates to enhance oil recovery. A mobility ratio greater than one is unfavourable because the water is more mobile than the oil and there is a great tendency for viscous fingering and early breakthrough [1].

\subsection{Viscous Fingering}

Viscous fingering occurs due to varying fluid mobilities. This is caused by varying fluid viscosities. If the displacing fluid such as water is more mobile than the oil, the water tends to overrun the oil irregularly towards the producing well. This together with heterogeneity in reservoir permeability traps lots of oil behind therefore lowering significantly, the oil recovery. Viscous fingering leads to poor recovery efficiencies due to early breakthroughs of the displacing phase [27].

\section{Methods}

This section comprises waterflooding and gas injection modeling and simulation using Eclipse Blackoil 100 simulator. The reservoir, well, PVT data are given.

\subsection{Case Study}

This study is conducted in Niger delta Field ABX2. The reservoir of focus in the Niger Delta Field ABX2 is an oil rim reservoir comprising of confined Late Cretaceous turbidite sandstone, with a combination drive mechanism (aquifer and solution gas). Secondary recovery is applied to this reservoir to investigate the performance of waterflooding and gas injection after primary recovery. Furthermore, sensitivity analyses were carried out on factors that can promote or relegate early water and/or gas breakthrough in the reservoir as this is a major concern of production in the Niger delta. In the reservoir, primary recovery only recovered $21 \%$ of the OIIP before the secondary recovery method was suggested because reservoir pressure was no longer sufficient to cause the economic recovery

The Assumptions used in this study are given below in Table 1:

1) The reservoir is homogenous;

Table 1. Reservoir data used in this work [28].

\begin{tabular}{cc}
\hline Parameter & Values \\
Porosity & 0.20 \\
Permeability & $1350 \mathrm{mD}$ \\
Wellbore ID & 5.921 inches \\
Interstitial water saturation & 0.2 \\
Reservoir pay thickness & $60 \mathrm{ft}$ \\
Reservoir depth & $8000 \mathrm{ft}$ \\
Reservoir acreage & $500 \mathrm{acres}$ \\
\hline
\end{tabular}


2) Reservoir uniformity and pay continuity;

3) The reservoir has constant porosity across all grid;

4) Constant permeability and thickness among layers;

5) The injected gas is immiscible with the reservoir fluid;

6) Injection and production rate were constant in the various injection scenario.

\subsection{PVT Parameters}

PVT data for this work was obtained from analyses conducted on fluid samples from Field ABX2 in the Niger Delta. The data for PVT as obtained from laboratory sampling already conducted on fluid samples from Field ABX2 is given in Table 2. The PVT data used for the simulation are given in Table 2.

\subsection{Reservoir and Well Models}

The reservoir is a 5-spot pattern with 1 producer and 1 injector for both the waterflooding and the gas injection cases.

The reservoir model is a 3D 3-phase model using ECLIPSE Blackoil simulator. The Cartesian model used in this model has a total of 1210 grids-50, 1, and 15 grids in $\mathrm{x}, \mathrm{y}$, and $\mathrm{z}$ directions respectively. The reservoir pay thickness is $60 \mathrm{ft}$ thick. Each cell is $242 \mathrm{ft} \times 1800 \mathrm{ft} \times 300 \mathrm{ft}(\mathrm{x}, \mathrm{y}$, and $\mathrm{z})$ direction respectively. The total area is 723 acres comprising of 725 active grids. The injection and production well are completely penetrating different layers of the reservoir. The injector well is injecting water and gas at a constant water rate and gas rate

The injection process was conducted at an 11,000 stb/day water injection rate and $1 \mathrm{MMscfd}$ gas injection rate. For both cases, the bottom-hole pressure at the injector well and the producer wells are 6000 psia and 500 psia respectively.

Figure 1 shows the reservoir grid block for waterflooding while Figure 2 shows the reservoir grid block for gas injection.

Table 2. PVT data.

\begin{tabular}{cc}
\hline Parameter & Values \\
\hline Initial reservoir pressure & $4500 \mathrm{psia}$ \\
Bubble point pressure & $3471 \mathrm{psia}$ \\
Formation volume factor & $1.25 \mathrm{rb} / \mathrm{stb}$ \\
Oil density & $51.8 \mathrm{lb} / \mathrm{ft}^{3}$ \\
Formation compressibility & $4.07 \mathrm{E}-6 \mathrm{psi}^{-1}$ \\
Water compressibility & $3.07 \mathrm{E}-6 \mathrm{psi}^{-1}$ \\
API gravity & $39 \mathrm{API}^{3}$ \\
Water density & $62.4 \mathrm{lb} / \mathrm{ft}^{3}$ \\
Gas density & $0.06054 \mathrm{lb} / \mathrm{ft}^{3}$ \\
viscosity & $4 \mathrm{cP}$ \\
Reservoir temperature & $178^{\circ} \mathrm{F}$ \\
\hline
\end{tabular}




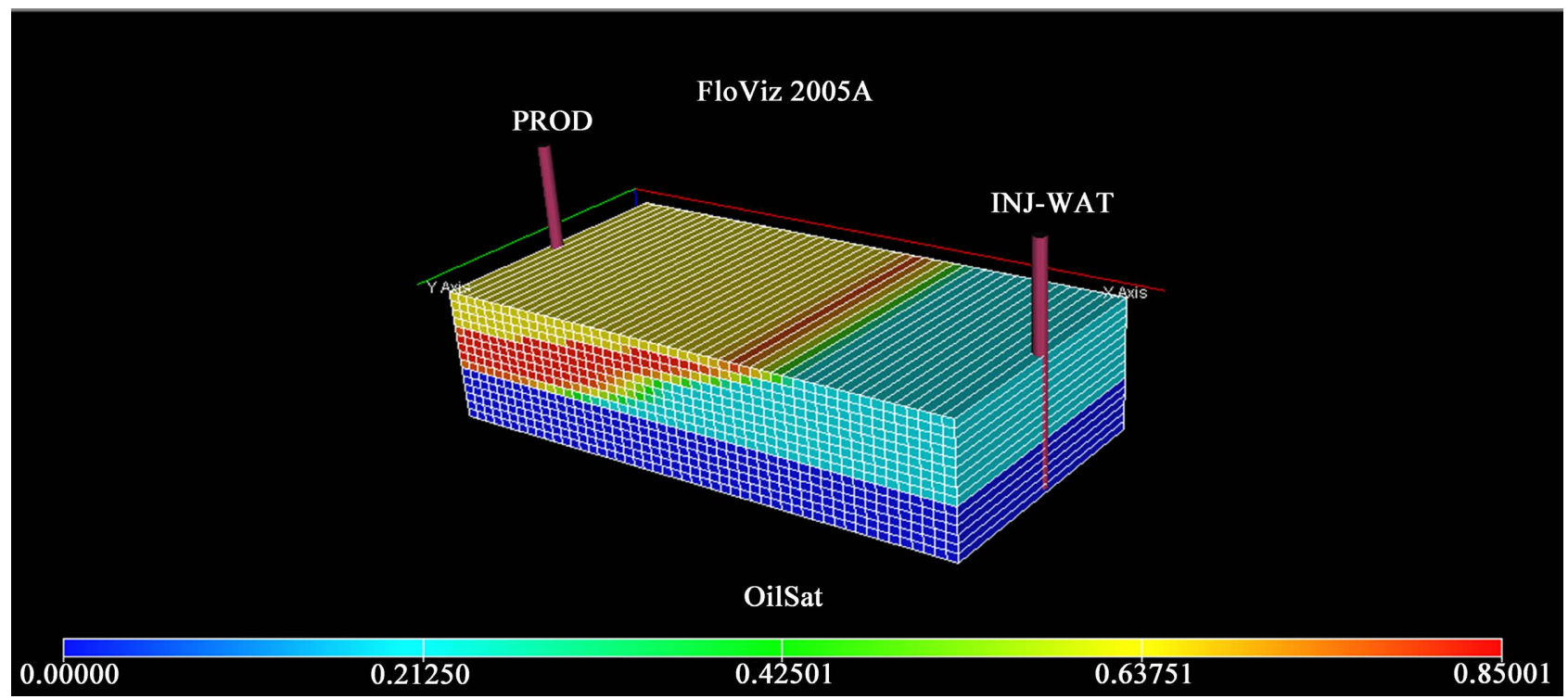

Figure 1. 3D view of well-placement during waterflooding.

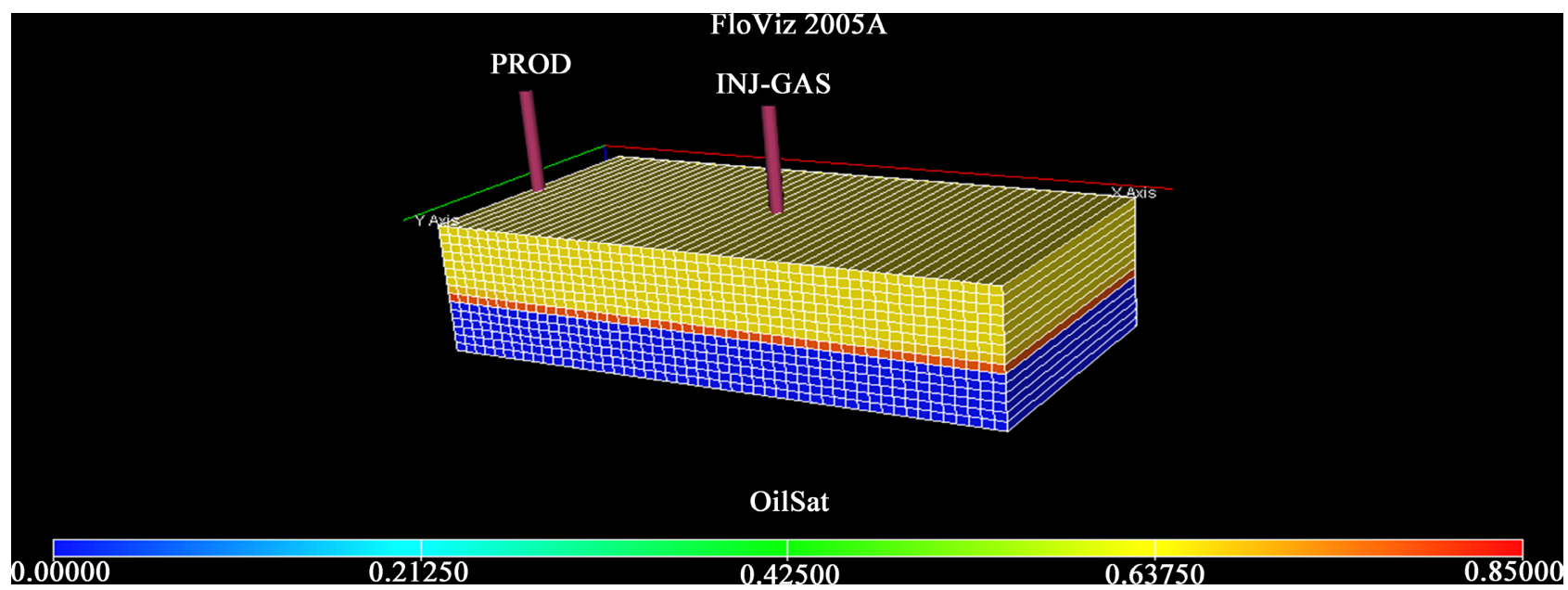

Figure 2. 3D view of well-placement during gas injection.

\section{Results and Discussions}

The results of the ECLIPSE Blackoil 100 simulator are presented for both the waterflooding and the gas injection.

\subsection{The Result of Field Reservoir Pressure (FPR) for Gas Injection and Waterflooding}

The field reservoir pressure drawdown plot for waterflooding and gas injection is presented in Figure 3.

From Figure 3, it can be observed that gas inject at the early time of the injection increased the reservoir pressure from the initial value of 4500 psia to a peak value of 5200 psia after 200 days of gas injection. But After 200 days of gas injection, a very sharp decline was realized as gas was continuously injected into the reservoir. The gas decline steep curve started from a peak value of 5200 psia at 


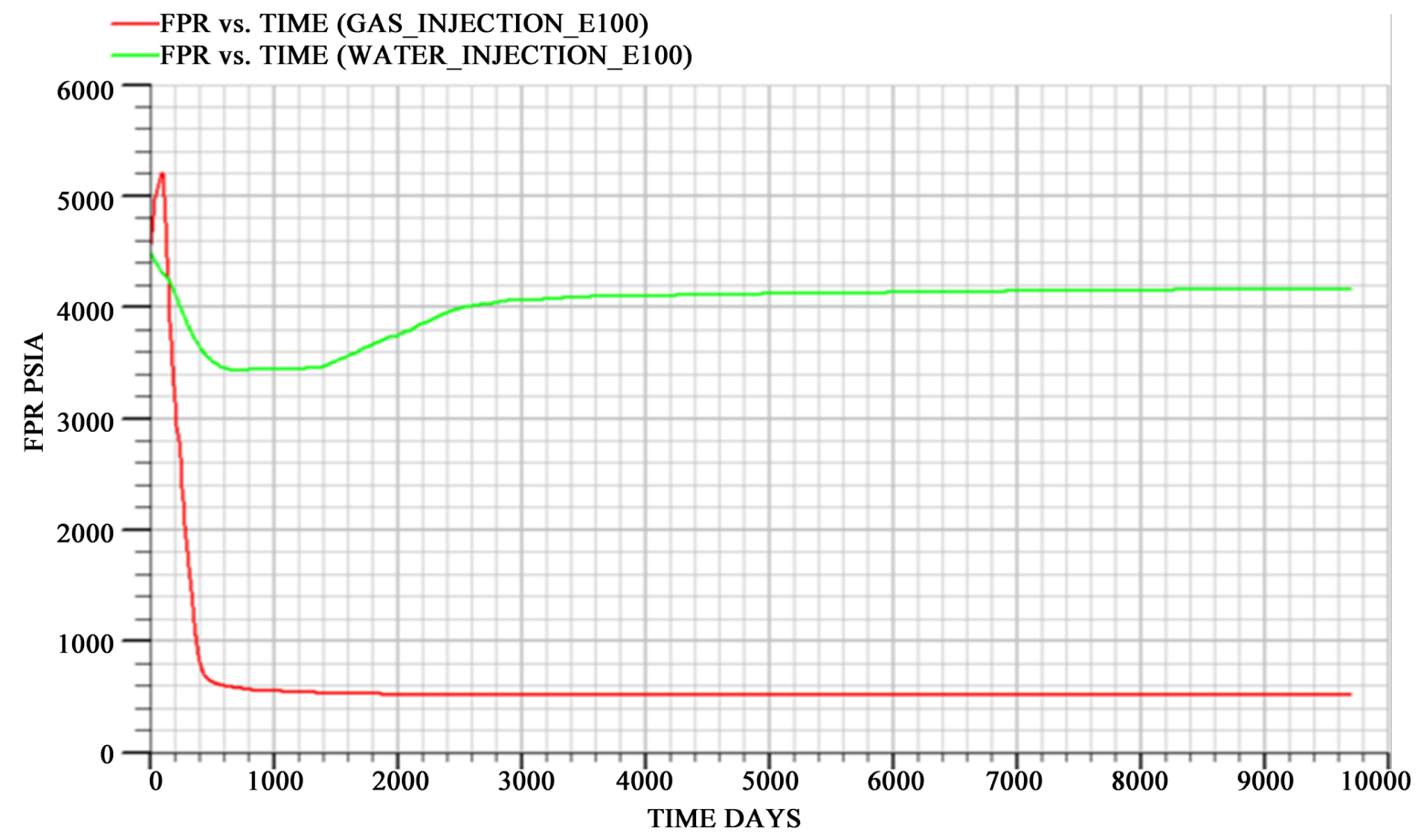

Figure 3. Plot of FPR against time for waterflooding and gas injection.

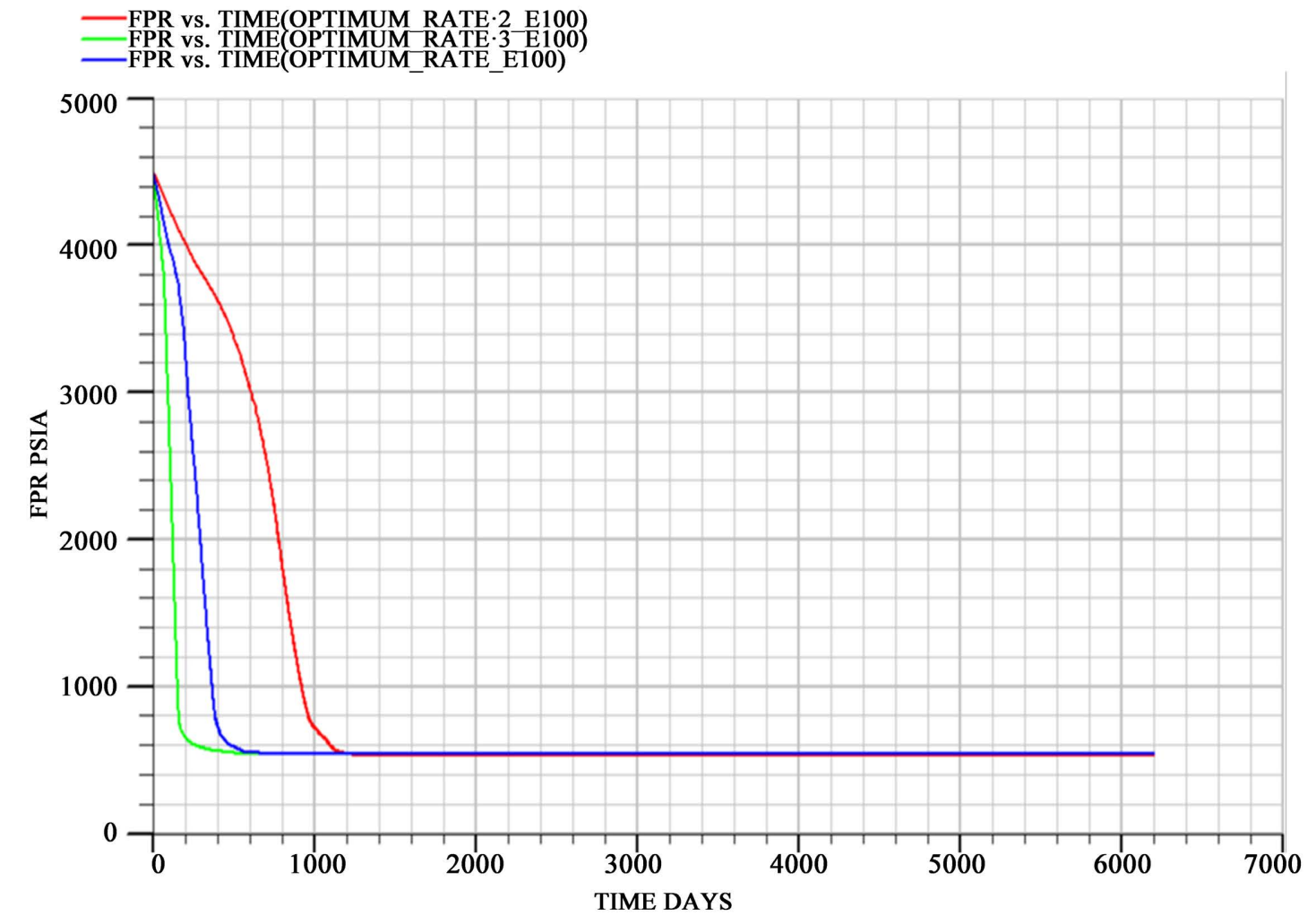

Figure 4. Plot of FPR against time for different liquid production rates for waterflooding.

day 200, to 600 psia after 600 days. Thus, after 400 days (from 200 days to 600 days) a pressure drop of 4600 psia has been experienced (5200 psia to 600 psia). The pressure further declined to 580 psia later than 600 days on continuous in- 
jection of gas and this pressure remained constant throughout the production period of the simulation.

For the waterflooding curve (the green line), the pressure dropped from 4500 psia to 3500 psia at the beginning of the production, the pressure was maintained at this point for a few days, then after, it rose steadily to a pressure of 4200 psia where it was maintained till the end of the simulation run. Thus it is seen that for the waterflooding, pressure maintenance was more realistic than in gas flooding as the pressure was maintained at 4200 psia after 2500 days till the end of the production period.

Figure 4 considers the field reservoir pressure drawdown for waterflooding and gas injection for several injection rates.

From Figure 4, the green line represents a liquid production rate of 10,000 $\mathrm{b} / \mathrm{d}$, the blue line represents a liquid production rate of $8000 \mathrm{~b} / \mathrm{d}$ while the red line represents a liquid production rate of $2500 \mathrm{~b} / \mathrm{d}$. From the figure, it can be realized that $2500 \mathrm{~b} / \mathrm{d}$ of liquids production has the highest FPR as compared to the highest liquid production rate which is $10,000 \mathrm{~b} / \mathrm{d}$. This it is expected that producing at $2500 \mathrm{~b} / \mathrm{d}$ will yield more recovery because the pressure is maintained more by producing at a lower rate.

\subsection{The Result of Field Oil Production Total (FOPT) for Gas Injection and Waterflooding}

The field oil production total refers to the total stock tank barrels of oil produced throughout the production process. It is given for both the waterflooding and the gas injection as seen in Figure 5.

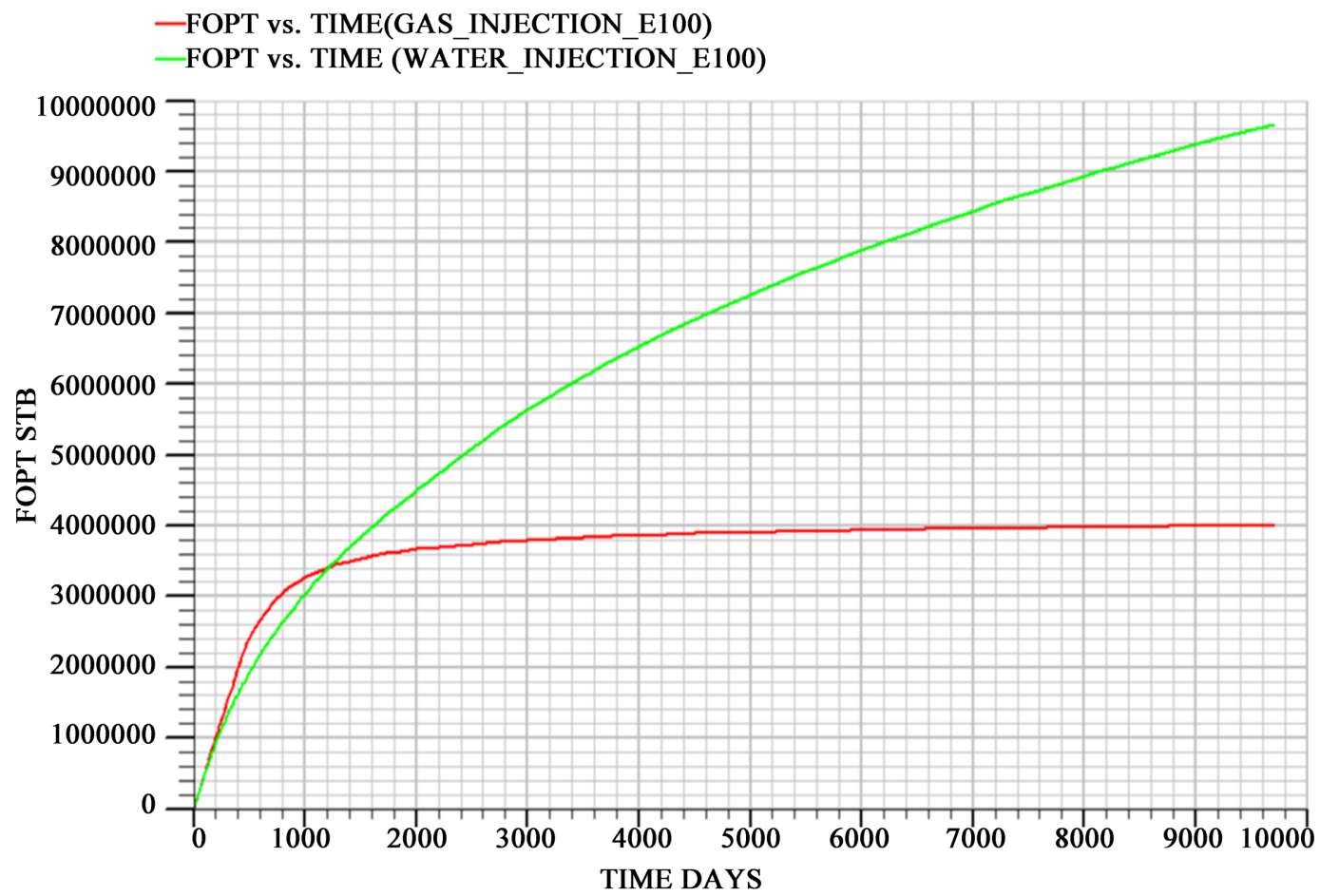

Figure 5. Plot of FOPT against time for waterflooding and gas injection. 
From Figure 5, it can be observed that at the initial time of producing more oil was recovered for gas injection than for waterflooding. From the start of the production to 1000 days, the total liquids recovered from gas injection were 3 , 200,000 stb of liquids while the total liquid recovered from waterflooding was $3,000,000$ stb of liquids. Thus, after 1000 days of injection, the gas injection was leading waterflooding in oil recovery with 200,000 stb of liquids. But gradually, as production progresses the liquids recovery from the two secondary recovery methods intersected each other at the 1200 day of production with equal liquids production rates of 3,400,000 stb of liquids respectively. After 1200 days of production, liquids production from waterflooding greatly surpassed that for gas injection till the end of the production process. After 9700 days of production, the total liquids production from waterflooding was 9,600,000 stb of liquids while the total liquids production from gas injection was 4,000,000 stb of liquid. The difference in total liquids recovery from the two injection schemes is 5,600,000 stb in favour of waterflooding. It is worthy to note that as is evident from the plot, the cumulative liquids production from gas injection remained constant from 5000 days to the end of the production process as injection of gas did not yield incremental liquids recovery in this period.

\subsection{The Result of Field Water Cut (FWCT) for Gas Injection and Waterflooding}

The Field Water Cut (FWCT) is the fraction of water in the total field liquid production rate and it was given in percentage for waterflooding and gas injection in Figure 6. In Figure 7, FWCT for gas injection for various liquid production rates was given.

From Figure 6, it can be observed that a lesser volume of water was produced during gas injection and more volume was produced during waterflooding as can be seen that $75 \%$ water cut was realized after 2000 days simulation period for waterflooding. This is attributed to the water production due to breakthrough of water which flows and was produced at the production wells. The waterflooding was noted with high water cut which will present production and surface handling problems as this will create additional expenses to handle.

Figure 7 represents the FWCT for different liquid production rates during gas injection. The sky blue line, the purple line, and the dark blue line represents liquid production rates of $10,000 \mathrm{~b} / \mathrm{d}, 5000 \mathrm{~b} / \mathrm{d}$, and $2500 \mathrm{~b} / \mathrm{d}$ respectively. From the plot, it can be observed that a liquid production rate of $2500 \mathrm{~b} / \mathrm{d}$ yields the highest water cut. At 1000 days, the FWCT from $2500 \mathrm{~b} / \mathrm{d}$ liquid production rate is $0.035 \%$ that of $5000 \mathrm{~b} / \mathrm{d}$ liquid production rate is $0.0138 \%$ while the FWCT for $10,000 \mathrm{~b} / \mathrm{d}$ liquid production is $0.0122 \%$. It can be seen that although the water cut from the gas injection is very low, the liquid production rate affects the water cut. Higher liquid production yields lower water cuts and vice versa.

\subsection{The Result of Field Oil Recovery Efficiency (FOE) for Gas Injection and Waterflooding}

The field oil recovery efficiency (FOE) for waterflooding and gas injection is 
—FWCT vs. TIME(GAS_INJECTION_E100)

FWCT vs. TIME (WATER_INJECTION_E100)

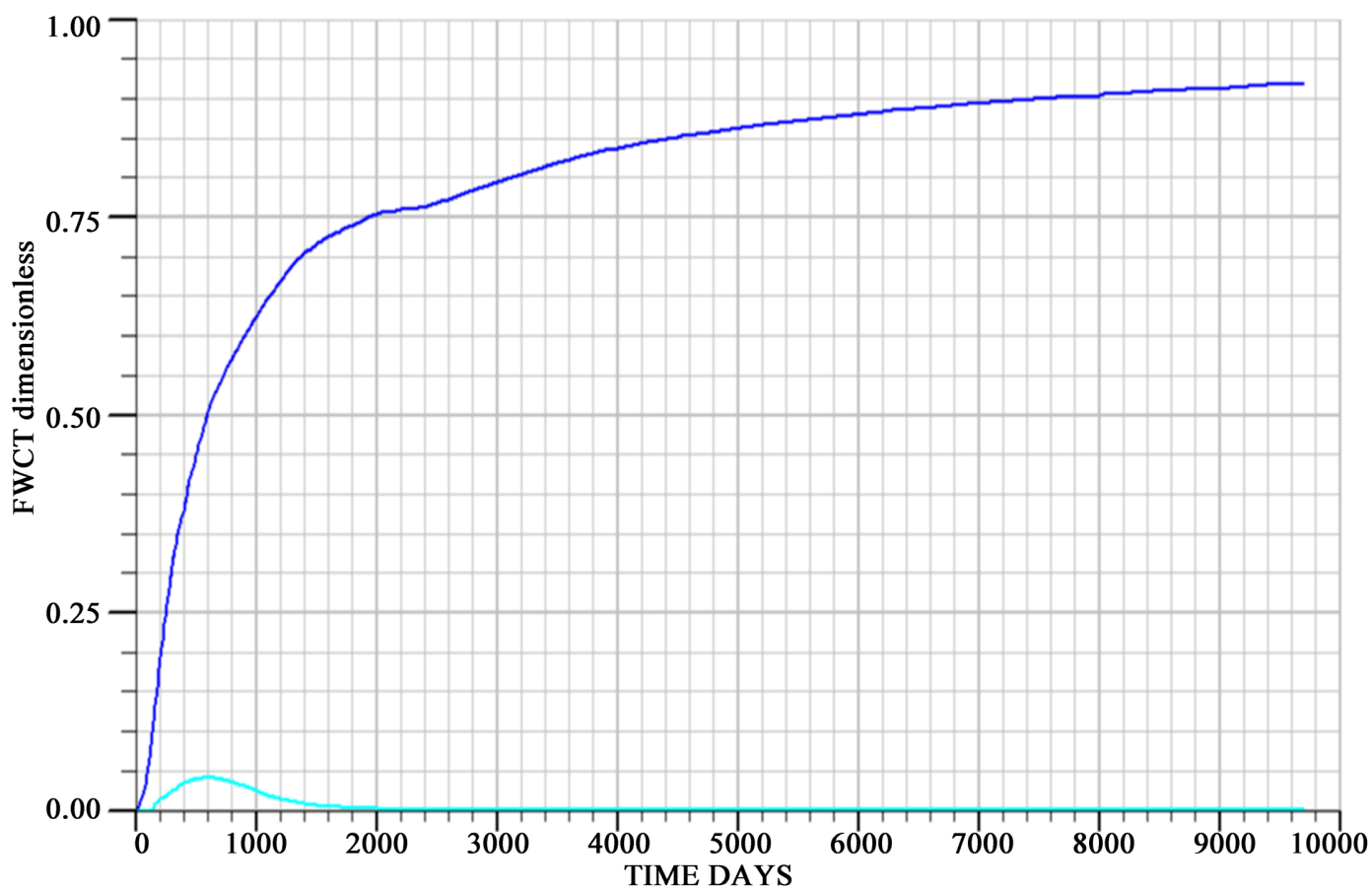

Figure 6. Plot of FWCT against time for gas injection and waterflooding.

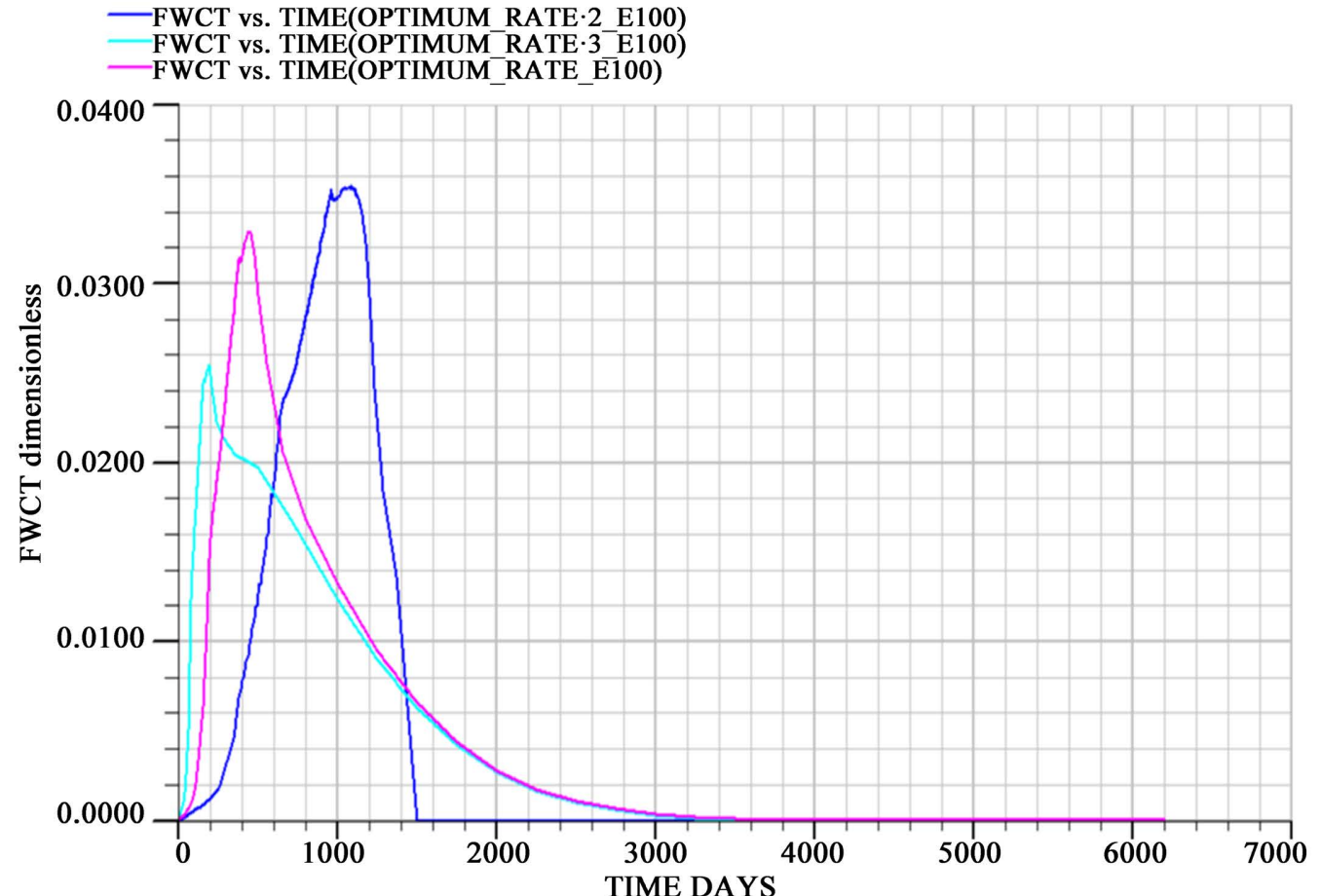

Figure 7. Plot of FWCT against time for different liquid production rates for gas injection.

given in this section. Sensitivities are also performed to see the effects of liquid production and well placement on the FOE both for waterflooding and gas injection. 
From Figure 8, it can be observed that for waterflooding, the efficiency of oil (FOE) recovery rose gradually from the beginning of production till the end of production while for gas injection, recovery efficiency at the beginning of production rose steadily, but at day 1020, rise in FOE was slow till the end of production. Waterflooding at the end of production gave an oil recovery efficiency of $38 \%$ while for gas injection, the oil recovery efficiency at the end of production was $16 \%$.

Figure 9 depicts the FOE for waterflooding and gas injection for different liquid production rates. From the figure, it can be observed that the least liquid production rate $(2500 \mathrm{stb} /$ day) gave the highest oil recovery efficiency while the highest liquid production rate $(10,000 \mathrm{stb} /$ day $)$ gave the least oil recovery efficiency.

In modeling, the effect of horizontal well-placement on oil production, the well was modeled at varying positions. The first well was placed at mid-rim, while the other was placed a little distance above mid-rim. From Figure 10, it can be observed that placing the well at mid-rim yields high FOE/FOPT than when the well is placed above the mid-rim or close to GOC.

Table 3 gives the total summary of the results of the simulation. It can be seen that waterflooding has better favourable results in the parameters considered than gas injection. It is worthy to note that the total oil recovery from primary recovery methods before secondary recovery was applied was 4,100,000 stb of oil while the total oil-in place after primary recovery was $25,000,000 \mathrm{stb}$ of oil.

\subsection{Discussion of Results}

Simulation has been done to determine the potential of waterflooding and gas injection as secondary recovery methods in Niger Delta Field ABX2.

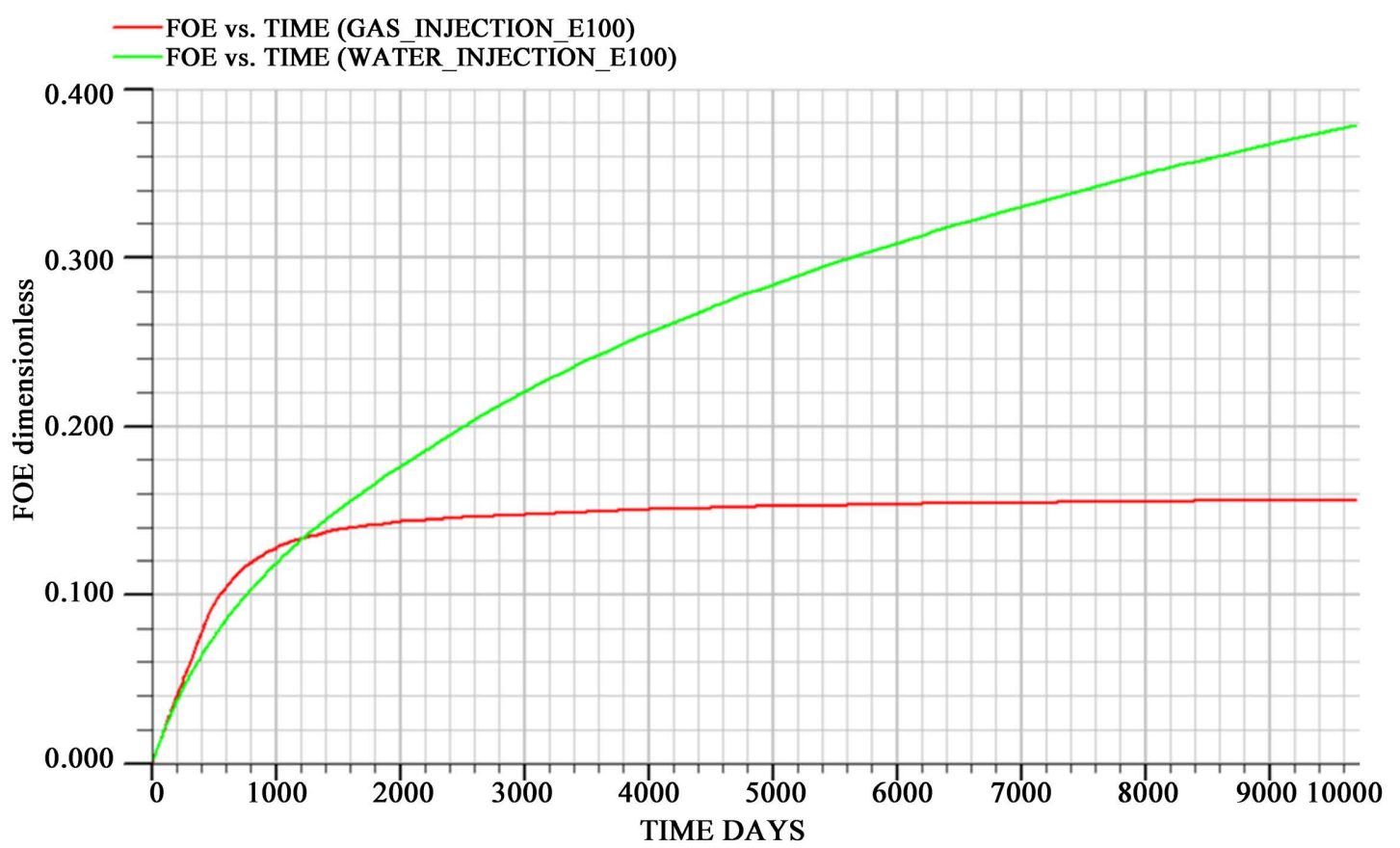

Figure 8. Plot of FOE against time for waterflooding and gas injection. 


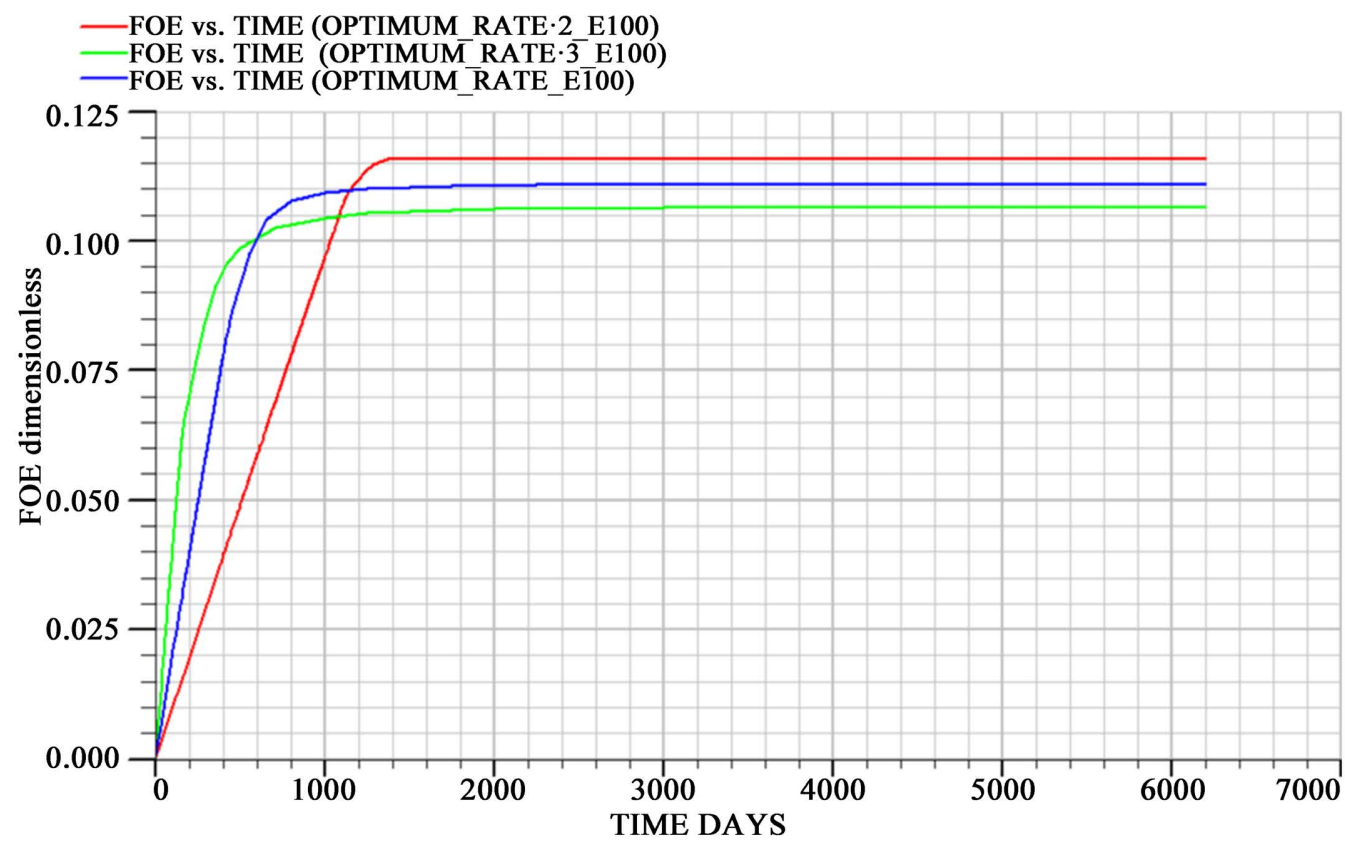

Figure 9. Plot of FOE against time for different liquid production rates.

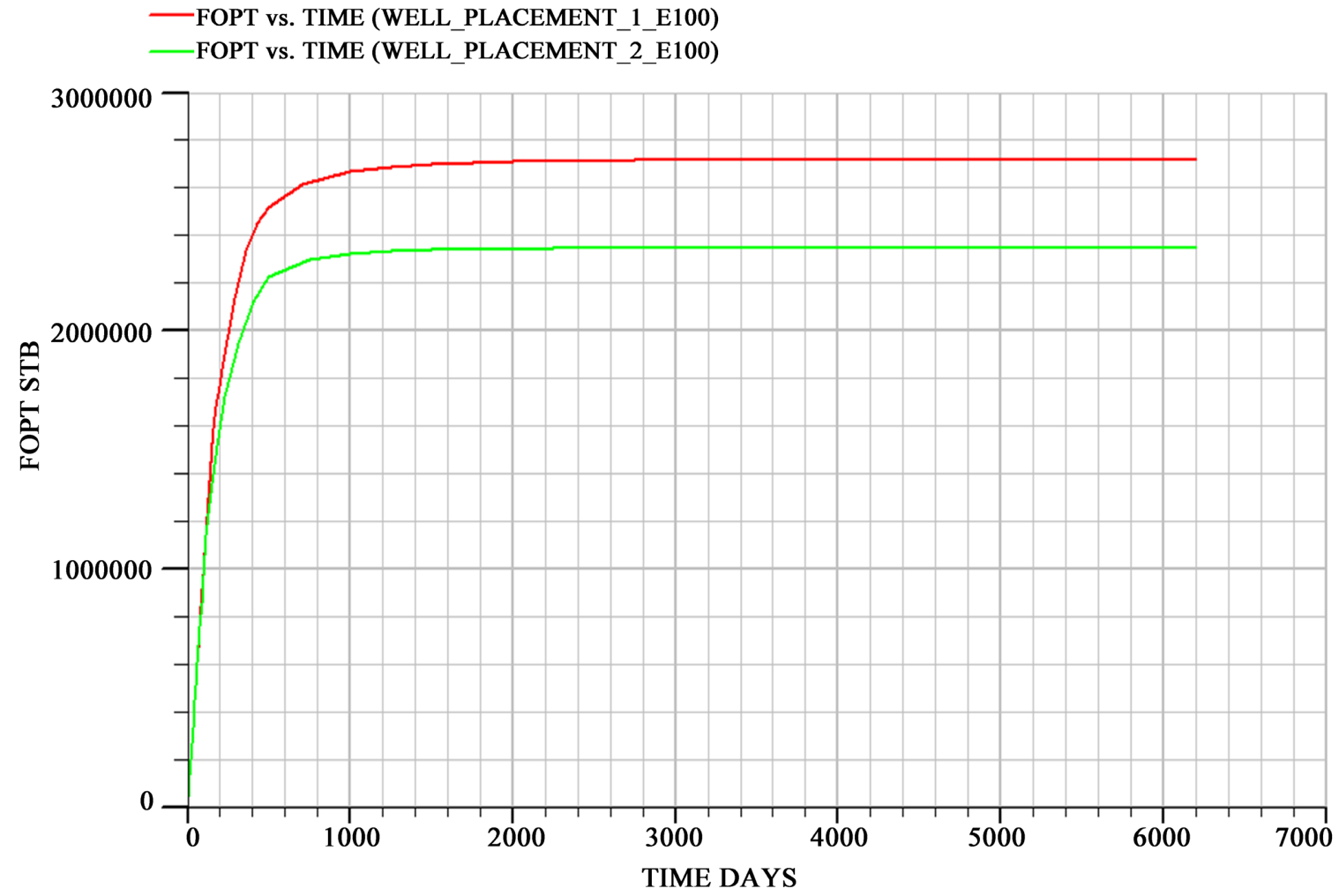

Figure 10. Plot of FOE against time for different well-placements.

The FPR was presented in Section 4.1 as depicted in Figure 3 and Figure 4. Figure 3 reveals that the gas injection increased the reservoir pressure more than waterflooding for early production. Because of early gas breakthroughs due to high-density contrasts between the reservoir oil and the gas, there was a significant 
Table 3. Summary of results of simulation for waterflooding and gas injection methods.

\begin{tabular}{ccc}
\hline Parameter & Waterflooding & Gas Injection \\
\hline Total Liquid production, stb & $9,600,000$ & $4,000,000$ \\
Total oil production, stb & $7,782,820$ & $3,276,980$ \\
Final field reservoir pressure, psia & 4000 & 580 \\
Water cut, \% & 92 & 0.01 \\
Field oil recovery efficiency, \% & 38 & 16 \\
\hline
\end{tabular}

drop in pressure resulting from the injection of gas. Subsequently, in the later periods of the production scheme, it was observed that waterflooding performed better than gas injection in maintaining the reservoir pressure. Figure 4 depicted the effect of liquid production rate on the FPR for the case of waterflooding. It was observed that producing at a lower rate has yields higher FPR per time than producing at higher rates. This is because producing at lower rates gives chance for more steady oil production and pressure maintenance. Thus the total oil recoverable from lower liquid rate production is expected to be higher than that for higher liquid production rates.

Section 4.2 gives the field oil production total (FOPT). The field oil production total refers to the total stock tank barrels of oil produced throughout the production process. More oil was produced from the waterflooding process than for gas injection because of better pressure maintenance in the waterflooding process. From Figure 5, it can be observed that the total liquid production for waterflooding at the end of the process is 9,600,000 stb of liquids while the total liquid production at the end of the process for gas injection is 4,000,000 stb of liquid. Thus, waterflooding gave an additional 5,600,000 stb of liquid when compared with gas injection. The oil produced from the waterflooding is $7,782,820$ stb while the oil produced using gas injection is $3,276,980 \mathrm{stb}$. Higher oil recovery was realized for waterflooding because water has higher mobility than gas in displacing oil to the production interval.

In Section 4.3, the field water cut for waterflooding and gas injection were presented. The total FWCT at the end of the production scheme for waterflooding is $92 \%$ while the total FWCT for gas injection at the end of the process is $0.01 \%$. The effects of liquid rates on FWCT presented in Figure 7 show that lower liquid rates yield higher FWCT for the gas lift injection considered. This is because lower liquid rates ultimately yield higher total liquid recoveries which translate to higher volumes of water produced and end-production water cut.

Section 4.4 gives the result of Field Oil Recovery Efficiency (FOE) for gas injection and waterflooding. It was observed that at the end of the production, waterflooding gave an oil recovery efficiency of $38 \%$ while for gas injection, the oil recovery efficiency at the end of production was $16 \%$. Higher recovery efficiency was expected for waterflooding because of the better reservoir pressure maintenance than the gas injection owing to the better mobility ratio in water- 
flooding than gas injection. When the effect of well placement was considered in Figure 10, it was observed that placing the well at mid-rim yields high FOE/FOPT than when the well is placed above the mid-rim or close to GOC because the mid-rim location gives more areal contact and less time for the fluids to be produced.

\section{Conclusions}

A simulation study has been performed on the determination of the performance of waterflooding and gas injection methods as secondary recovery means in the recovery of Niger Delta Field ABX2. The simulation was performed for waterflooding and gas injection using ECLIPSE Blackoil 100 reservoir simulator and results were analyzed and compared. From the results and analyses, the following conclusions are made:

1) Niger Delta Field ABX2 is mature for secondary recovery method owing to the reduction in reservoir pressure from primary depletion;

2) Due to the light nature of the reservoir oil, the waterflooding is a good option for the field;

3) Early gas breakthrough due to large density and viscosity contrast between the reservoir oil and injected gas hampered the success of the gas injection process;

4) Waterflooding produces $38 \%$ oil recovery efficiency while gas injection produced $16 \%$ oil recovery efficiency, a difference of $22 \%$ additional efficiency was gotten for waterflooding when compared to gas injection;

5) The total oil recovered from waterflooding is $7.78 \mathrm{MMstb}$ while the total oil recovery for the gas injection was 3.28 MMstb giving a difference of 4.5 MMstb;

6) High water cut was associated with waterflooding. This was because of the breakthrough of water;

7) Waterflooding performed better than gas injection for the simulation of Field $\mathrm{ABX} 2$ reservoir in areas of oil production, and pressure maintenance;

8) Waterflooding is recommended as the choice recovery method to be applied to Field ABX2 because of the favourable production performance;

9) To delay breakthrough and increase ultimate recovery in waterflooding, it is recommended that the viscosity of the injected water be increased using polymers. This will increase the mobility of water in the waterflooding scheme.

\section{Conflicts of Interest}

The authors declare no conflicts of interest regarding the publication of this paper.

\section{References}

[1] Mai, A. and Kantzas, A. (2008) Mechanisms of Heavy Oil Recovery by Low Rate Waterflooding. Paper Presented at the Canadian International Petroleum Conference, Alberta, June 2008, Paper No. PETSOC-2008-156. https://doi.org/10.2118/2008-156 
[2] Adeniyi, O.D., Nwalor, J.U. and Ako, C.T. (2008) A Review on Waterflooding Problems in Nigeria's Crude Oil Production. Journal of Dispersion Science and Technology, 29, 362-365. https://doi.org/10.1080/01932690701716101

[3] Ayoub, M.A., Shabib-Asl, A., AbdellahiZein, A.M., Elraies, K.A. and MohdSaaid, I.B. (2015) Recovery Optimization of an Oil Reservoir by Water Flooding under Different Scenarios: A Simulation Approach. Research Journal of Applied Sciences, Engineering, and Technology, 4, 357-372. https://doi.org/10.19026/rjaset.10.2499

[4] Ikram, O. (2012) Reserves Augmentation by Designing an Optimum Waterflood Pattern with Black Oil Simulator. IOSR Journal of Mechanical and Civil Engineering, 2, 62-77.

[5] Bartelsa, W.B., Mahanib, H., Bergb, S., Hassanizadeha, S.M. (2019) Literature Review of Low Salinity Waterflooding from a Length and Time Scale Perspective. Fuels, 236, 338-353 https://doi.org/10.1016/j.fuel.2018.09.018

[6] Wang, L. and Wei, L. (2011) Study on Advanced Water Injection Time in Low Permeability Reservoir. Energy and Power Engineering, 3, 194-197. https://doi.org/10.4236/epe.2011.32025

[7] Udy, J., Hansen, B., Maddux, S., Petersen, D., Heilner, S., Stevens, K., Lignell, D. and John, D.H. (2017) Review of Field Development Optimization of Waterflooding, EOR, and Well Placement Focusing on History Matching and Optimization Algorithms. Processes, 5, Article No. 34. https://doi.org/10.3390/pr5030034

[8] Jia, H. and Deng, L. (2018) Oil Reservoir Water Flooding Flowing Area Identification Based on the Method of Streamline Clustering Artificial Intelligence. Petroleum EXploration and Development, 45, 312-319.

[9] Awolayo, A., Sarma, H. and Al Sumaiti, A. (2014) A Laboratory Study of the Ionic Effect of Smart Water for Enhancing Oil Recovery in Carbonate Reservoirs. SPE EOR Conference at Oil and Gas West Asia, Muscat, March 2014, Paper No. SPE-169662-MS. https://doi.org/10.2118/169662-MS

[10] Vasconez, N., Sabyrgali, Y. and Mackay, E. (2016) Core Flood Modeling of Ion-Exchange during Low Salinity Waterflooding. AAPG Latin America \& Caribbean Region, Geoscience Technology Workshop, Buenos Aires, 16-18 November 2016, 16-18.

[11] Zhang, R. and Jia, H. (2021) Production Performance Forecasting Method Based on Multivariate Time Series and Vector Autoregressive Machine Learning Model for Waterflooding Reservoirs. Petroleum Exploration and Development, 48, 201-211. https://doi.org/10.1016/S1876-3804(21)60016-2

[12] Li, J., Lei, Z., Li, S., Zhang, R., Wang, F., Yu, T., et al. (2016) Optimizing Waterflood Performance to Improve Injector Efficiency in Fractured Low-Permeability Reservoirs Using Streamline Simulation. Paper Presented at the SPE Kingdom of Saudi Arabia Annual Technical Symposium and Exhibition, Dammam, April 2016, Paper No. SPE 182779. https://doi.org/10.2118/182779-MS

[13] Nasralla, R.A., van der Linde, H.A., Marcelis, F.H., Mahani, H., Masalmeh, S.K., Sergienko, E., et al. (2016) Low Salinity Waterflooding for a Carbonate Reservoir Experimental Evaluation and Numerical Interpretation. Abu Dhabi International Petroleum Exhibition \& Conference, Abu Dhabi, 7-10 November 2016, 7-10.

[14] Xie, Q., Ma, D., Liu, Q. and Lv, W. (2015) Ion Tuning Waterflooding in Low Permeability Sandstone: Coreflooding Experiments and Interpretation by Thermodynamics and Simulation. Paper Prepared for Presentation at the International Symposium of the Society of Core Analysts Held in St. John's Newfoundland and Labrador, Canada, 16-21 August 2015.

[15] Brouwer, D.R. and Jansen, J.D. (2004) Dynamic Optimization of Waterflooding 
with Smart Wells Using Optimal Control Theory. SPE Journal, 9, 391-402. https://doi.org/10.2118/78278-PA

[16] van Essen, G., Zandvliet, M., Van den Hof, P., Bosgra, O. and Jansen, J.-D. (2009) Robust Waterflooding Optimization of Multiple Geological Scenarios. SPE Journal, 14, 202-210. https://doi.org/10.2118/102913-PA

[17] Alhuthali, A.H., Oyerinde, D., Gupta, A.D. (2007) Optimal Waterflood Management Using Rate Control. SPE Annual Technical Conference and Exhibition, SPE-102478PA. https://doi.org/10.2118/102478-MS

[18] Sarma, P., Durlofsky, L.J., Aziz, K. and Chen, C. (2006) Efficient Real-Time Reservoir Management Using Adjoint-Based Optimal Control and Model Updating. Computational Geosciences, 10, 3-36. https://doi.org/10.1007/s10596-005-9009-Z

[19] Wang, D.F., Li, Z.X., Zhao, J.Y., He, Y.H. and Hao, F. (2007) Advance Water-Flooding Theory for Low-Permeability Reservoirs and Its Application. Acta Petrolei Sinica, 28, 78-81-86.

[20] Liu, P.C., Li, F.H., Li, K. and Wang, Y.D. (2007) Advance Water Injection in Reverse Nine-Spot Well Pattern in Block 119 of Xinli Oilfield. Journal of Oil and Gas Technology, 29, 120-123.

[21] Zhang, L., Kang, Q., Yao, J., Gao, Y., Sun, Z., Liu, H. and Valocchi, A.J. (2015) Pore Scale Simulation of Liquid and Gas Two-Phase Flow Based on Digital Core Technology. Science China Technological Sciences, 58, 1375-1384. https://doi.org/10.1007/s11431-015-5842-Z

[22] Alvarado, V. and Manrique, E. (2010) Enhanced Oil Recovery: An Update Review. Energies, 3, 1529-1575. https://doi.org/10.3390/en3091529

[23] Tiab, D. and Donaldson, E.C. (2004) Petrophysics: Theory and Practice of Measuring Reservoir Rock and Fluid Transport Properties. 2nd Edition, Gulf Professional Publishing, Burlington.

[24] Ahmed, T. (2006) Reservoir Engineering Handbook. 3rd Edition, Gulf Professional Publishing, Elsevier, Burlington.

[25] Thomas, C.J. (2008) Petrophysics: Theory and Practice of Measuring Reservoir Rock and Fluid Transport Properties. 2nd Edition, Gulf Professional Publishing, Elsevier, Burlington.

[26] Almutairi, F.H., Davies, D.R. and Singh, S. (2007) Enhancing Production from Thin Oil Column Reservoirs Using Intelligent Completions. Paper Presented at the Asia Pacific Oil and Gas Conference and Exhibition, Jakarta, October 2007, Paper No. SPE-110207-MS. https://doi.org/10.2118/110207-MS

[27] Tewari, R., Malik, M., Ali, A.H.A. and Naganathan, S. (2005) Improved Heavy Oil Recovery from Thin Reservoirs through Horizontal Well Placement and Intelligent Perforations. Paper Presented at the SPE International Improved Oil Recovery Conference in Asia Pacific, Kuala Lumpur, December 2005, Paper No. SPE-97649-MS. https://doi.org/10.2118/97649-MS

[28] Abili, J.D., Izuwa, N.C., Onyejekwe, I.M. and Ekwueme, S.T. (2021) Simulation Studies on Determination of Displacement and Areal Sweep Efficiencies for Hot $\mathrm{CO}_{2}$ Flooding in Niger Delta Heavy Oilfield. International Journal of Oil, Gas and Coal Engineering, 9, 24-35. https://doi.org/10.11648/j.ogce.20210902.13 


\section{Nomenclature}

FOE: Field oil recovery efficiency;

FOPT: Field oil production total;

FPR: Field reservoir pressure;

FWCT: Field water cut;

GOC: Gas-oil contact;

ID: Internal diameter;

$\mathrm{mD}$ : Millidarcy;

OIIP: Oil-in-initial Place;

PVT: Pressure-volume-temperature. 